\title{
A Multiband Monopole Antenna with the Inverted-Trapezoidal CPW Feeding
}

\author{
Quanqi Zhang, ${ }^{1,2}$ Yuanxin Li, ${ }^{1,2}$ Zhixi Liang, ${ }^{1,2}$ Hong-Zhou Tan,,2 and Yunliang Long1,2 \\ ${ }^{1}$ Department of Electronics and Communication Engineering, Sun Yat-Sen University, Guangzhou 510006, China \\ ${ }^{2}$ SYSU-CMU Shunde International Joint Research Institute, Shunde 528300, China \\ Correspondence should be addressed to Quanqi Zhang; zhangquanqi@foxmail.com
}

Received 29 January 2014; Accepted 30 April 2014; Published 25 May 2014

Academic Editor: Byungje Lee

Copyright (c) 2014 Quanqi Zhang et al. This is an open access article distributed under the Creative Commons Attribution License, which permits unrestricted use, distribution, and reproduction in any medium, provided the original work is properly cited.

\begin{abstract}
A multi-band monopole antenna with the improved inverted-trapezoidal coplanar waveguide (CPW) feeding is presented. The antenna has a simple planar structure, and occupies an area of $15 \mathrm{~mm} \times 50 \mathrm{~mm}$. The proposed antenna consists of an improved inverted-trapezoidal CPW-fed patch, and a series of monopole strips with different length. This monopole antenna utilizes the advantages of the CPW feeding to simplify the structure of the antenna into a single metallic level and achieve high antenna gain. The improved inverted-trapezoidal CPW-fed patch and a meander shorting strip lead to a better impedance matching result and multi-band operation. The experimental results of the proposed antenna are shown and discussed. The antenna generates two wide bands centered at about 900 and $2200 \mathrm{MHz}$ to cover the GSM850/GSM900/DCS/PCS/UMTS/LTE2300/2500 bands and the $2.4 \mathrm{GHz}$ WLAN operation. Meanwhile the antenna covers the $4 \mathrm{G}$ bands of China Telecom $(2370-2390 \mathrm{MHz} / 2635-2655 \mathrm{MHz})$, China Unicom (2300-2320 MHz/2555-2575 MHz) and China Mobile (1880-1900 MHz/2320-2370 MHz/2575-2635 MHz), too
\end{abstract}

\section{Introduction}

With the continuous upgrading of the personal communication system, antenna design becomes a bottleneck for mobile phones where multiple communication services are integrated in the same platform. Potential mobile phone antennas should combine different characteristics such as multiband, low profile, and high antenna gain [1]. The antenna should cover GSM850/GSM900/DCS/PCS/UMTS/ LTE2300/2500 bands/4G band and $2.4 \mathrm{GHz}$ WLAN band at the same time. A lot of different techniques are documented to balance these characteristics, such as PIFA [2], chip inductors [3], biplanar coupling feed [4], and DSPSL [5]. They achieve multiband with antenna gain from about -0.8 to $1 \mathrm{dBi}$ in lower band and from about -2 to $3.8 \mathrm{dBi}$ in upper band generally.

On the other hand, higher antenna gain can be easily achieved through CPW-fed antennas due to the fact that it gets low radiation leakages [6]. CPW-fed antennas introduce good impedance matching [7], shunt and series connections on the same side without using via holes which result in its simple configuration, manufacturing advantages, and low cost [8]. However, CPW-fed antennas are seldom applied in mobile phones. It is difficult for CPW-fed antennas to operate in multiband in the limited space of mobile phones [9]. Traditional CPW-fed antennas are mainly used in WLAN system [10], UWB communication system [11, 12], and the digital TV applications [13].

Another improved design proves infeasible when decreasing the size of the antenna and at the same time maintaining its bandwidth. It is a big challenge. However, compared with the conventional monopole and mobile phone antennas, the design presented in this paper is simple and wideband. A multiband monopole antenna with the invertedtrapezoidal CPW feeding in this paper is simple and wellmatched with good efficiency and improved bandwidth that is suitable for the potential ultrathin mobile phone. The CPWfed antenna requires a small area of $15 \mathrm{~mm} \times 50 \mathrm{~mm}$. The proposed antenna has a simple structure, which comprises an improved conformal inverted-trapezoidal CPW-fed patch at the bottom of the antenna to match the impedance at both operating frequencies, and it is easy to be fabricated. The multiband operation is achieved through a series of monopole strips on the same side of the dielectric substrate. 


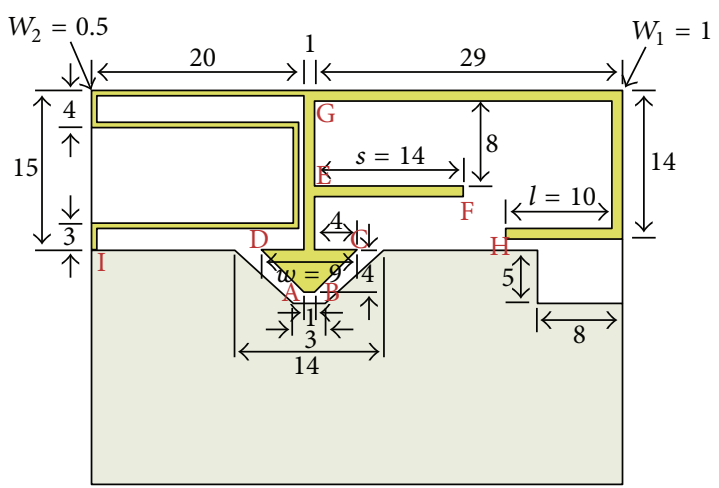

(a)

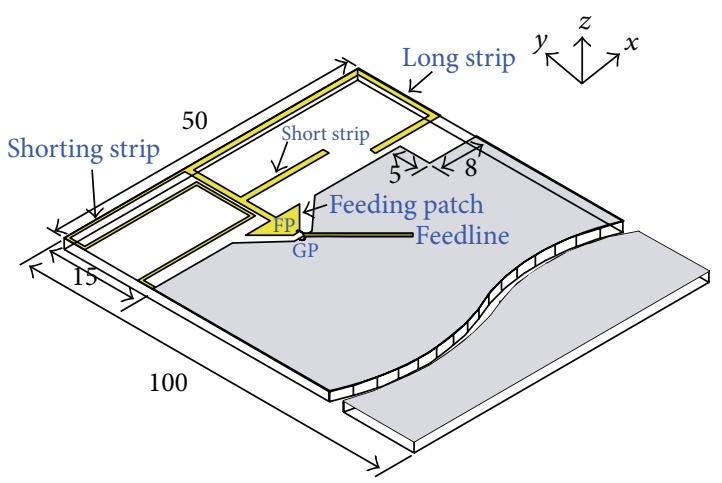

FP: feeding point

GP: grounding point

(b)

FIGURE 1: Geometry of the proposed multiband monopole antenna with the inverted-trapezoidal coplanar waveguide (CPW) feeding (unit: $\mathrm{mm}$ ).

The proposed monopole is implemented in the nonground portion with a nonstraight edge facing the main ground plane on the system circuit board. The proposed design could provide two bands to cover GSM800/900 in the lower band and GSM 1800/1900/UMTS/LTE2300/2500/2.4 GHz WLAN/4G band of China Telecom/4G band of China Unicom/4G band of China Mobile in the upper band. Design consideration and experimental performances of the proposed antenna are studied and presented.

\section{Design of the Proposed Antenna}

The geometry of the multiband monopole antenna with the improved inverted-trapezoidal CPW feeding is shown in Figure 1. A $1.6 \mathrm{~mm}$ thick FR4 substrate of $100 \mathrm{~mm} \times 50 \mathrm{~mm}$ with a dielectric constant of $\varepsilon_{r}=4.4$ is used as the system circuit board with a nonground portion of about $15 \mathrm{~mm} \times$ $50 \mathrm{~mm}$. A $5 \mathrm{~mm} \times 8 \mathrm{~mm}$ ground perturbation is configured to improve the matching result.

The antenna is fed by an improved conformal invertedtrapezoidal CPW-fed patch (section ABCD), which is connected to a $50 \Omega$ feedline. A width varying slot line is formed by cutting a notch around the inverted-trapezoidal CPWfed patch (section $A B C D$ ) which has a bottom-width $1 \mathrm{~mm}$, a top-width $w=9 \mathrm{~mm}$ as the preferred length here, and a height $4 \mathrm{~mm}$. By selecting a proper top-width $w$ of this patch, a good impedance matching of the proposed antenna is found.

The proposed antenna is mainly composed of a meander shorting strip (section GI) on the left, a long strip (section $\mathrm{GH}$ ) on the right, and a short strip (section EF) between the long strip and the ground on the same side. The length of the strip is given [14-16]:

$$
\begin{aligned}
l & =\frac{1}{4} \lambda_{\text {eff }}=\frac{c}{4 f \varepsilon_{\text {eff }}}, \\
\varepsilon_{\text {eff }} & =\frac{\varepsilon_{r}+1}{2}+\frac{\varepsilon_{r}-1}{2}\left(1+\frac{5 h}{s}\right)^{-(1 / 2)} .
\end{aligned}
$$

The line length and line width of section GI, section GH, and section EF are $73 \mathrm{~mm}$ and $0.5 \mathrm{~mm}, 43 \mathrm{~mm}$ and $1 \mathrm{~mm}$, and $14 \mathrm{~mm}$ and $1 \mathrm{~mm}$, respectively. The end (point I) of the narrow meander shorting strip is the shorting point to the top edge of system ground. The proposed antenna with dimensions given in Figure 1 has been fabricated and tested.

\section{Discussion}

Figure 2 shows the comparison of the simulated and measured $S_{11}$ of the antennas among the case with a simple shorting strip (Ref1), the case with a meander shorting strip (Ref2), and the proposed antenna shown in Figure 1. A direct CPW feeding is used in both Ref1 and Ref2 shown in Figure 2(b). Three antennas in the figure have the same corresponding dimensions. In the lower band, few effects on impedance of both Ref1 and Ref2 at about $900 \mathrm{MHz}$ are seen. In the upper band, Refl is formed by just one resonant mode at about $2500 \mathrm{MHz}$, whose bandwidth is far from covering the desired frequency. Ref2 generates three resonant modes at $1820 \mathrm{MHz}, 2050 \mathrm{MHz}$, and $2550 \mathrm{MHz}$, and it covers the required band for applications of the mobile phone with different resonant depths. The results indicate that the meander shorting strip could provide double resonances at $1820 \mathrm{MHz}$ and $2050 \mathrm{MHz}$ and an acceptable impedance matching at $2550 \mathrm{MHz}$. In the proposed antenna shown in Figure 1, the improved inverted-trapezoidal CPW-fed patch replaces the direct CPW feeding in Ref1 and Ref2. It leads to better impedance matching in a wide range of operating frequencies. In Figure 2(a), $S_{11}$ in the upper band is less than $-10 \mathrm{~dB}$ in most parts, with its lowest at $-30 \mathrm{~dB}$, which means the desired impedance matching has been obtained here.

Effects of the improved inverted-trapezoidal CPW-fed patch (section ABCD) are studied in Figure 3. The invertedtrapezoidal CPW-fed patch with different top-widths could significantly affect the impedance matching. The results of $S_{11}$ of the width $w$ that varied from 8 to $10 \mathrm{~mm}$ are presented. Few effects on the excited resonant mode at about $900 \mathrm{MHz}$ are seen. In the upper bands, most resonant depths have reduced to $-10 \mathrm{~dB}$. When the top-width is narrow $(w=8 \mathrm{~mm}$ ) or wide $(w=10 \mathrm{~mm})$, serious mismatching is observed. 


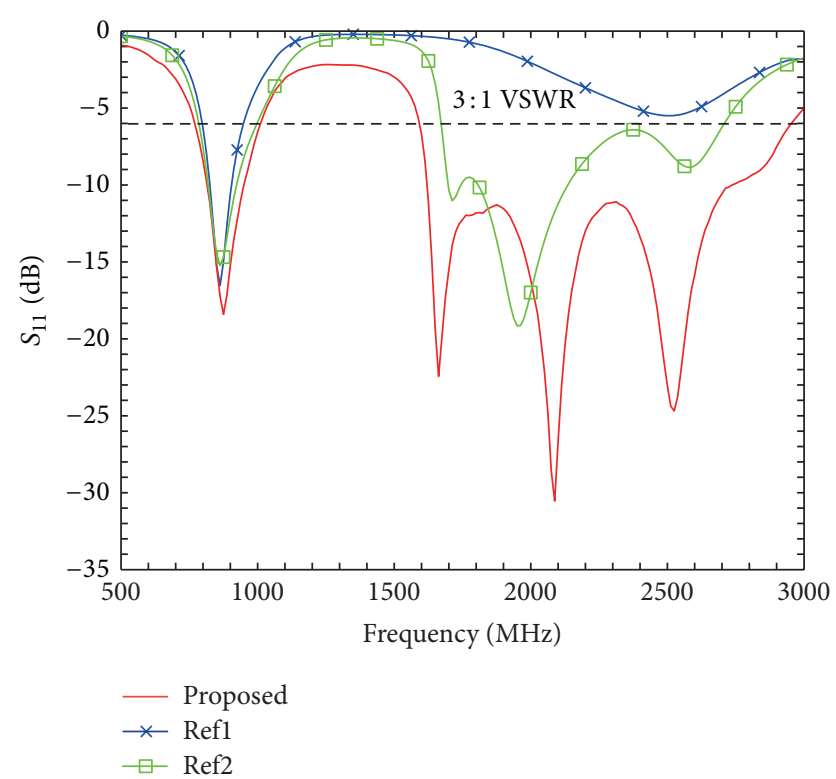

(a)

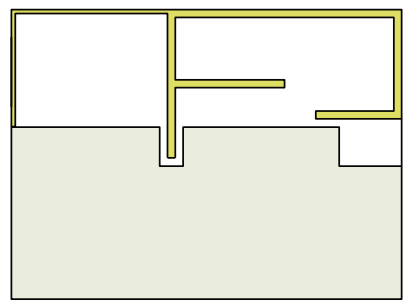

Ref1

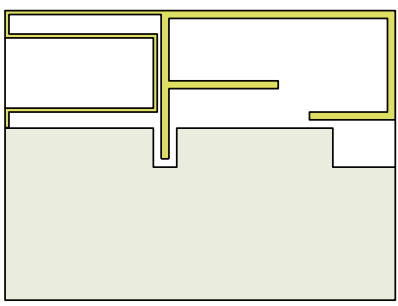

Ref2 (b)

Figure 2: (a) Comparison of the simulated $S_{11}$. (b) Corresponding antenna with a simple shorting strip (Ref1) and the corresponding antenna with a meander shorting strip (Ref2).

The impedance matching is optimized by the shaping of the inverted-trapezoidal patch and controlling the top-width $w$. The improved inverted-trapezoidal CPW-fed patch replaces the direct CPW feeding that is used in Figure 2(b). The higher resonant frequencies caused by the meander shorting strip improve substantially. As the width $w$ varies from 8 to $10 \mathrm{~mm}$, different results of electronic field at $2000 \mathrm{MHz}$ around the protruded ground that is under the meander shorting strip are presented in Figure 4. Stronger $E$-field is observed around the feeding in the ground, when the width $w$ is equal to $8 \mathrm{~mm}$ or $10 \mathrm{~mm}$. The impedance matching is optimized by the width $w$ that is equal to $9 \mathrm{~mm}$. The beveled ground plane and the CPW-fed patch could result in a smooth transition from one resonant mode to another and ensure good impedance match, especially at the upper frequencies.

Figures 5 and 6 show the simulated $S_{11}$ with different length $l$ of the long strip (section GH) and different length $s$ of the short strip (section EF) in the proposed antenna. With the increased length $l$, the resonant mode in the lower band contributed by the long strip is shifted to lower frequencies. The lower band is related to the long strip, and the variations

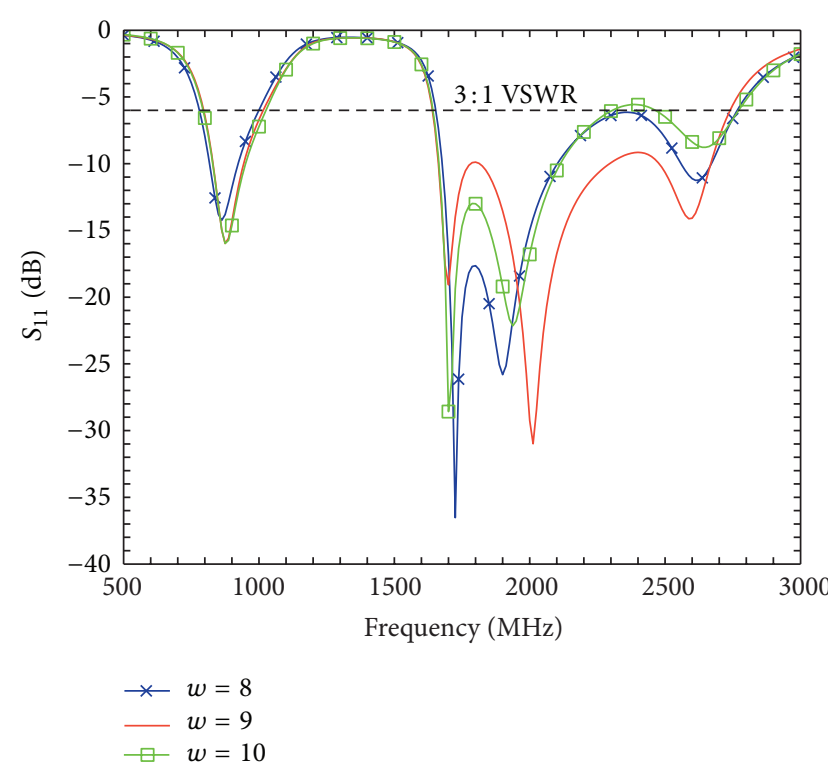

FIgURE 3: Simulated $S_{11}$ as a function of the top-width $w$ of the $\mathrm{CPW}$-fed patch; other dimensions are the same as given in Figure 1 (unit: $\mathrm{mm}$ ).

in the length $l$ also result in varying impedance matching results for the upper band. In Figure 8, the meander shorting strip (section GI) and the short strip (section EF) lead to the generation of the three resonance behaviors. By tuning the length $s$ of the short strip, the antenna's upper band can be controlled. In addition, a $5 \mathrm{~mm} \times 8 \mathrm{~mm}$ ground perturbation mentioned above increases the lower resonant depth by 2 $3 \mathrm{~dB}$ because more radiation space is created.

In Figure 7, efficient radiating parts are found in different parts of the proposed antenna and ground plane, according to different frequencies. At $900 \mathrm{MHz}$, stronger $E$-field is observed in the long strip (section $\mathrm{GH}$ ) and the meander shorting strip (section GI) and it is coupled by the terminal of the long strip around the ground perturbation. The perturbation improves the matching result of the lower band and could make the antenna get low radiation leakages, whereas, at $1820 \mathrm{MHz}$ and $2050 \mathrm{MHz}$, stronger $E$-field is found in the meander shorting strip (section GI) and the long strip terminal (section GH, $l$ in Figure 1), and at $2550 \mathrm{MHz}$, stronger $E$-fields are seen in the short strip (section $\mathrm{EF}$ ) and the meander shorting strip (section GI). At the upper frequencies, relatively strong excited $E$-field distributions are found in the protruded ground that surrounds the invertedtrapezoidal CPW-fed patch, compared to the lower frequency at $900 \mathrm{MHz}$. The results indicate that the inverted-trapezoidal $\mathrm{CPW}$-fed patch is an important radiating part, especially at the upper frequencies.

\section{Results}

Results of the measured and simulated $S_{11}$ are shown in Figure 8 . The prototype of the proposed antenna is based on the foregoing optimized parameters and is fabricated as shown in Figure 9. Two wide operating bands centered 

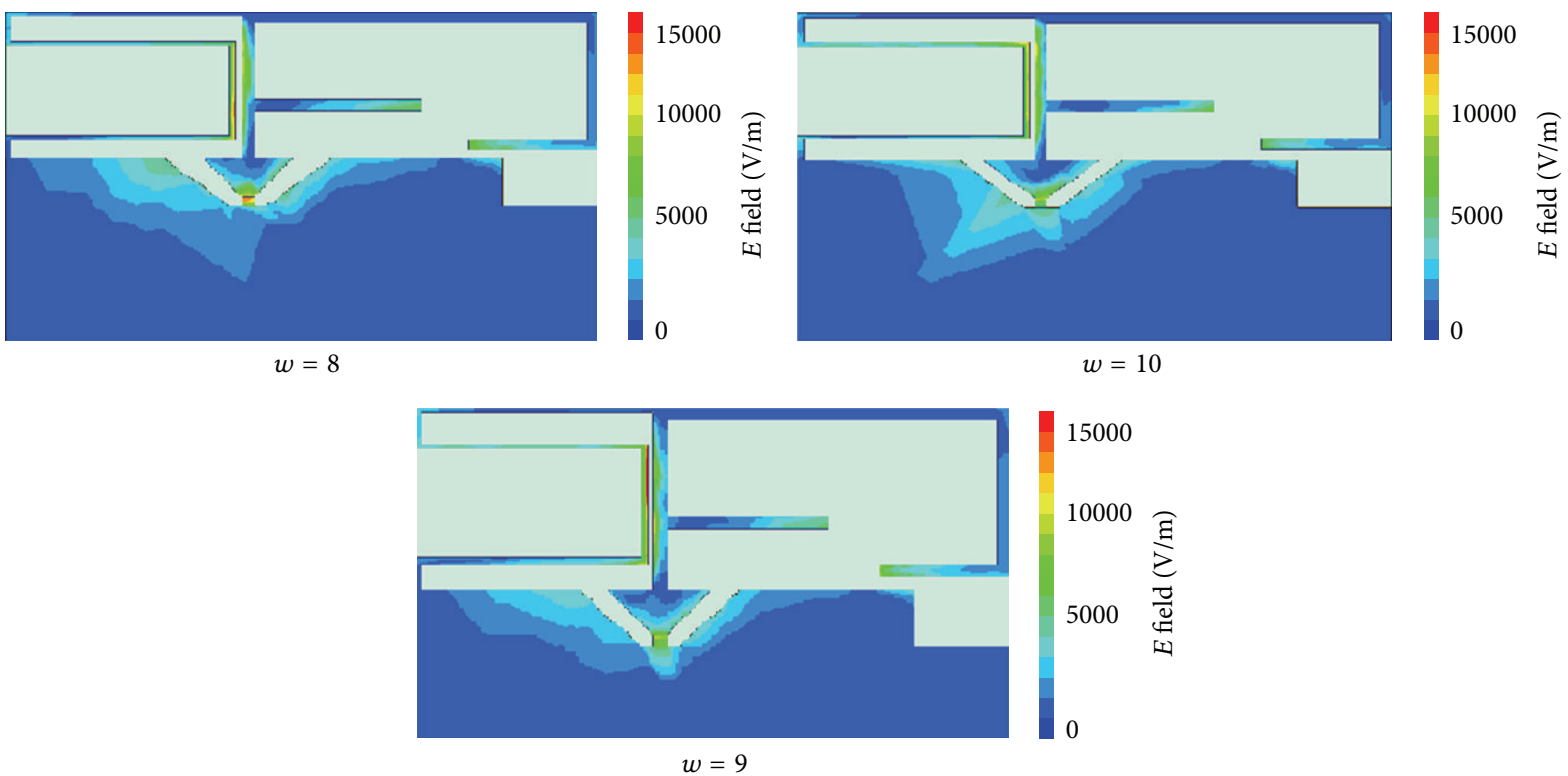

FIgURE 4: E-field distributions at $2000 \mathrm{MHz}$ (unit: mm).

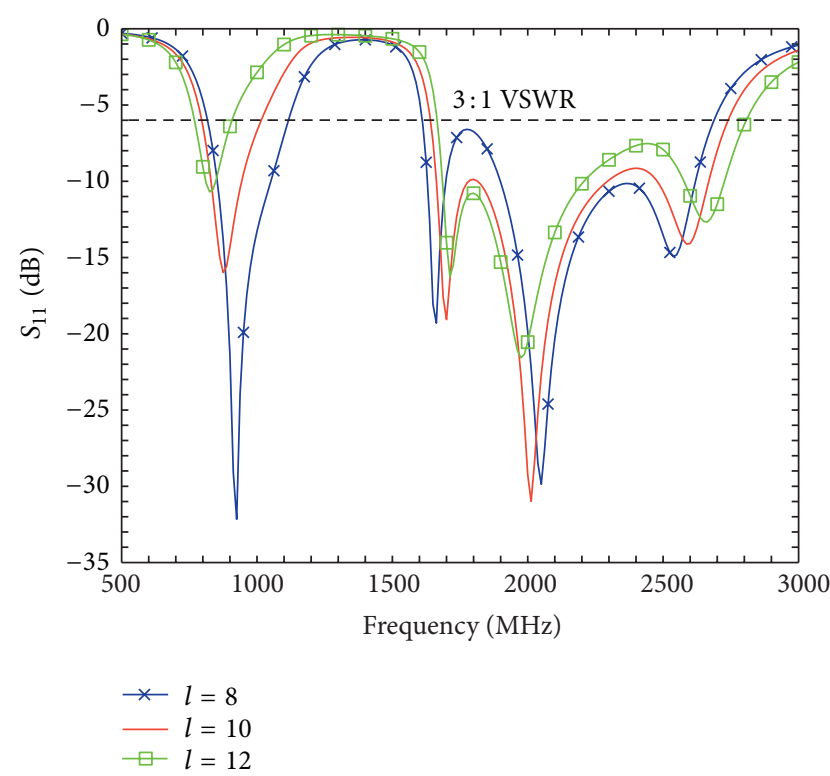

FIGURE 5: Simulated $S_{11}$ as a function of the length $l$ of the long strip; other dimensions are the same as given in Figure 1 (unit: $\mathrm{mm}$ ).

at about $900 \mathrm{MHz}$ and $2200 \mathrm{MHz}$ are achieved. With a definition of $3: 1 \mathrm{VSWR}$, which is generally used for mobile phone antenna design, the lower band has a bandwidth of $240 \mathrm{MHz}(770-1010 \mathrm{MHz})$ covering the GSM850/900 operations. The upper band formed by three resonances shows a bandwidth of $1360 \mathrm{MHz}(1590-2950 \mathrm{MHz})$, which covers the DCS/PCS/UMTS/LTE2300/2500/2.4 GHz WLAN/4G band of China Telecom/4G band of China Unicom/4G band of China Mobile operation.

Figure 10 plots the measured radiation patterns in different planes ( $x y$-plane, $x z$-plane) at each frequency. At $900 \mathrm{MHz}$, dipole-like radiation patterns are shown, and the

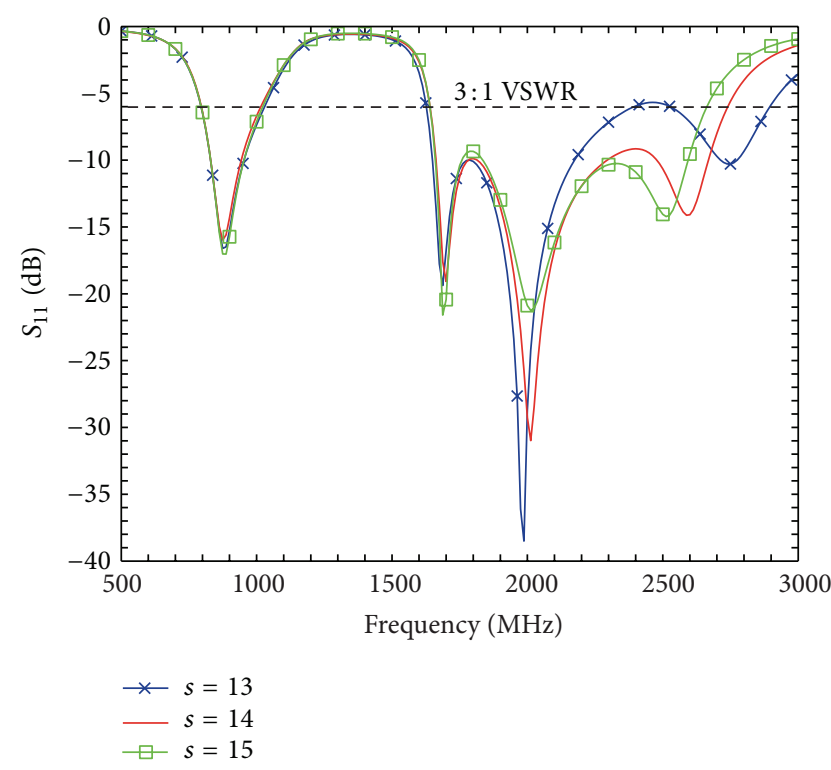

FIgURE 6: Simulated $S_{11}$ as a function of the length $s$ of the short strip; other dimensions are the same as given in Figure 1 (unit: $\mathrm{mm}$ ).

radiation patterns for frequencies over the lower band (770$1010 \mathrm{MHz}$ ) are similar to those plotted at $900 \mathrm{MHz}$. For upper band at $1820 \mathrm{MHz}, 2050 \mathrm{MHz}$, and $2550 \mathrm{MHz}$, the radiation patterns become rapidly varied in the patterns.

The measured antenna gain and simulated radiation efficiency are presented in Figure 11. The antenna gain is about $1.8-2.3 \mathrm{dBi}$ and the radiation efficiency ranges from $65 \%$ to $82 \%$ in the $780-1050 \mathrm{MHz}$ band. Over the $1650-2650 \mathrm{MHz}$ band, the antenna gain is about $3.5-5 \mathrm{dBi}$ and the radiation efficiency ranges from about $68 \%$ to $89 \%$. The antenna gain is lower around $2400 \mathrm{MHz}$, which results from the different resonant depths of $S_{11}$ in Figure 2. As shown in Figure 8 and 


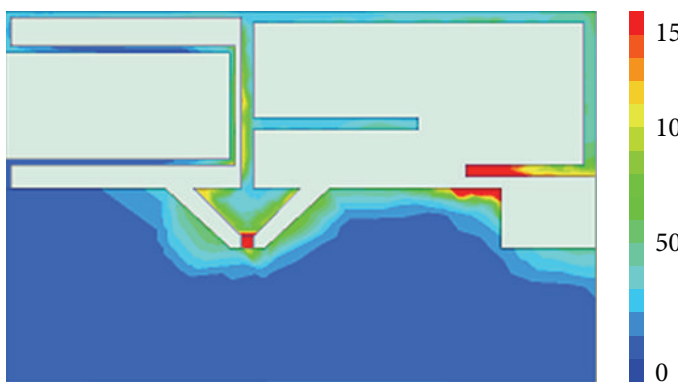

$900 \mathrm{MHz}$

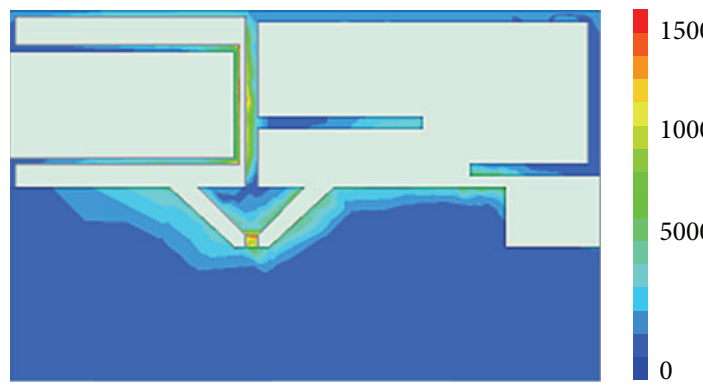

$2050 \mathrm{MHz}$
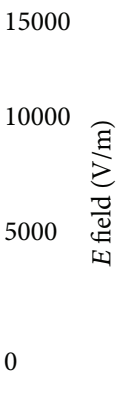

15000
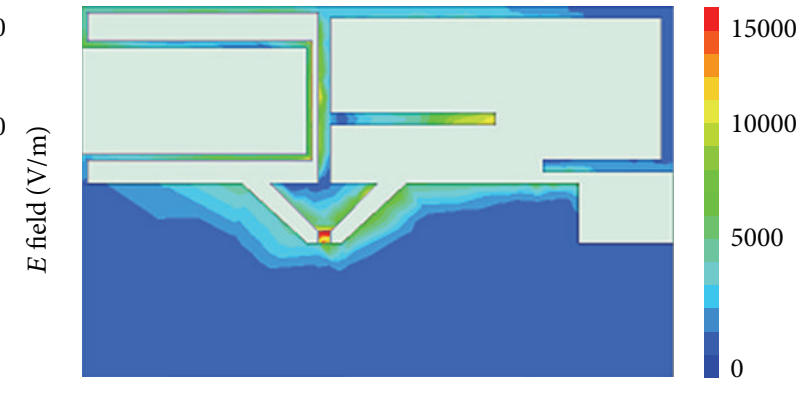

$2550 \mathrm{MHz}$

FIGURE 7: E-field distributions at 900, 1820, 2050, and $2550 \mathrm{MHz}$.

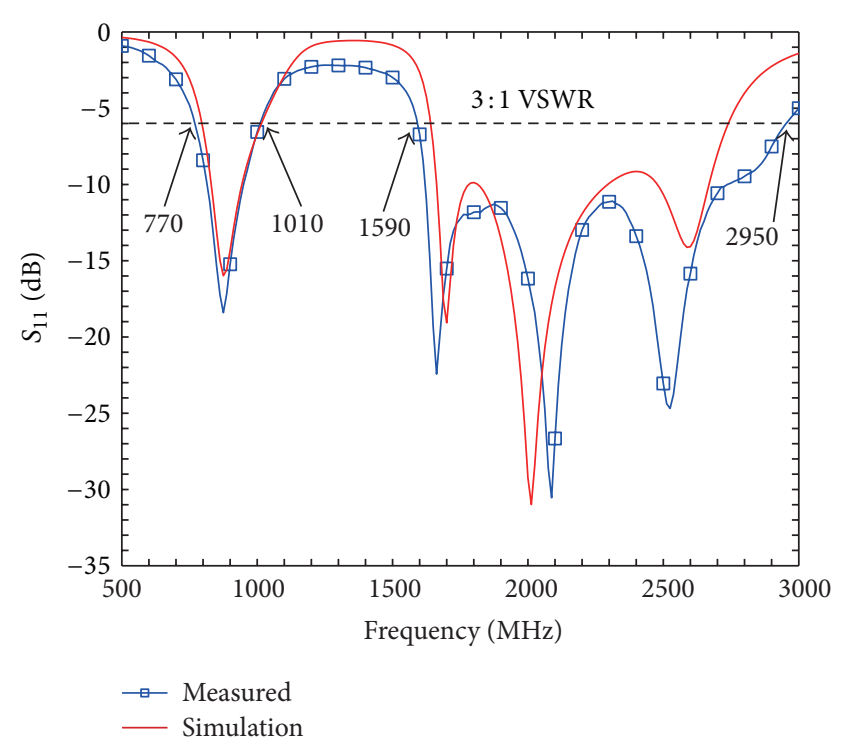

FIGURE 8: Measured and simulated $S_{11}$ of the proposed antenna.

Figure 11, the impedance matching around $2050 \mathrm{MHz}$ and $2550 \mathrm{MHz}$ is better than that around $2400 \mathrm{MHz}$.

\section{Conclusion}

A multiband monopole antenna with the improved invertedtrapezoidal feeding has been proposed. The antenna has a simple structure and is easy to be printed on an area of $15 \mathrm{~mm} \times 50 \mathrm{~mm}$. The proposed antenna with an improved inverted-trapezoidal CPW-fed patch has low radiation leakages and enables shunt and series connections on the

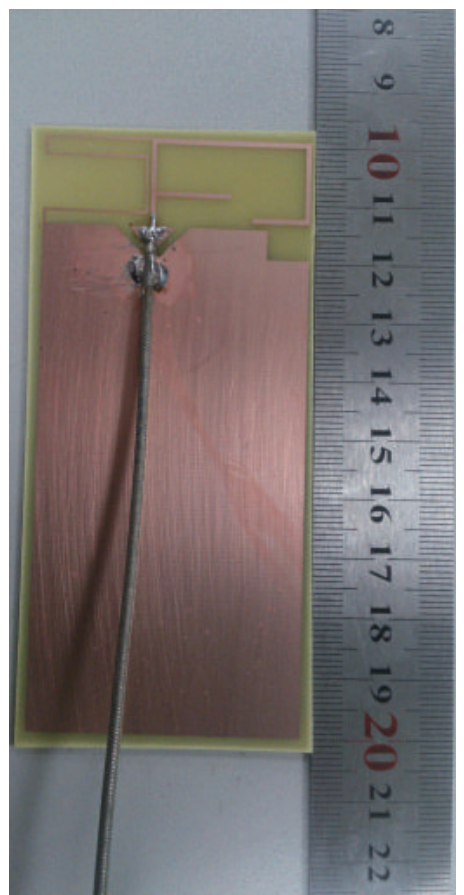

FIGURE 9: Fabricated prototype of the proposed antenna.

same side. The improved gains are got. Two wide operating bands covering the $770-1100 \mathrm{MHz}$ and $1690-2950 \mathrm{MHz}$ bands for the desired GSM850/GSM900/DCS/PCS/UMTS/ LTE2300/2500/2.4 GHz WLAN/4G band of China Telecom/4G band of China Unicom/4G band of China Mobile operation have been obtained. It could be made well-matched with good efficiency and improved bandwidth. The obtained 

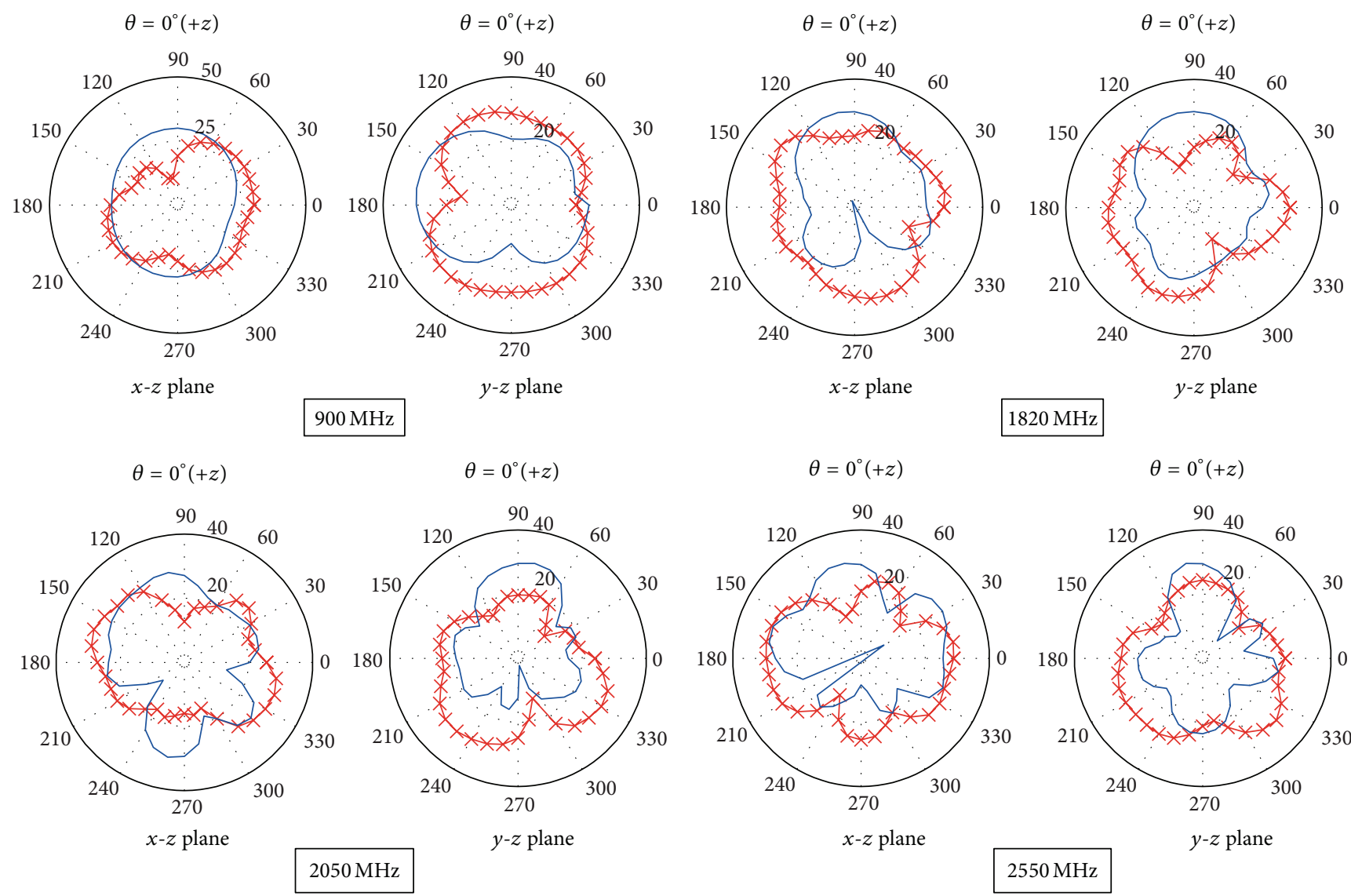

$\star E_{\theta}$

$\times E_{\theta}$

$-E_{\phi}$

$-E_{\phi}$

FIGURE 10: Measured radiation patterns at 900, 1820, 2050, and $2550 \mathrm{MHz}$ of the proposed antenna.

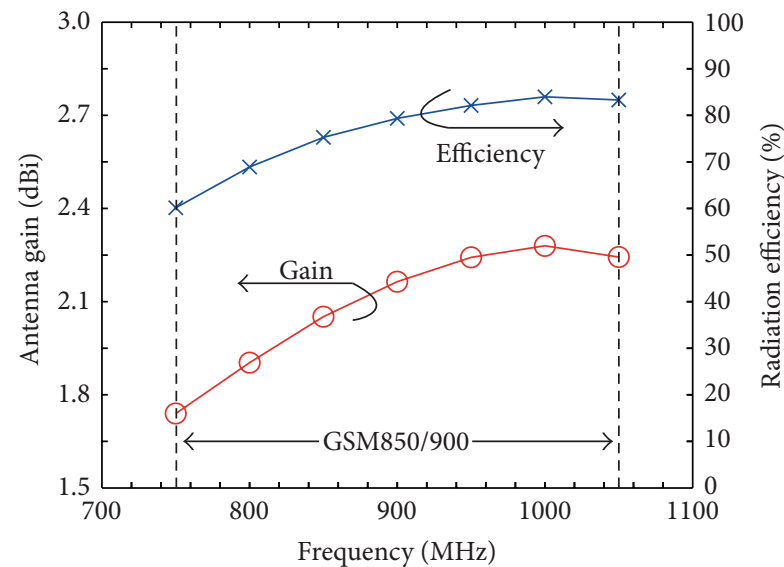

(a)

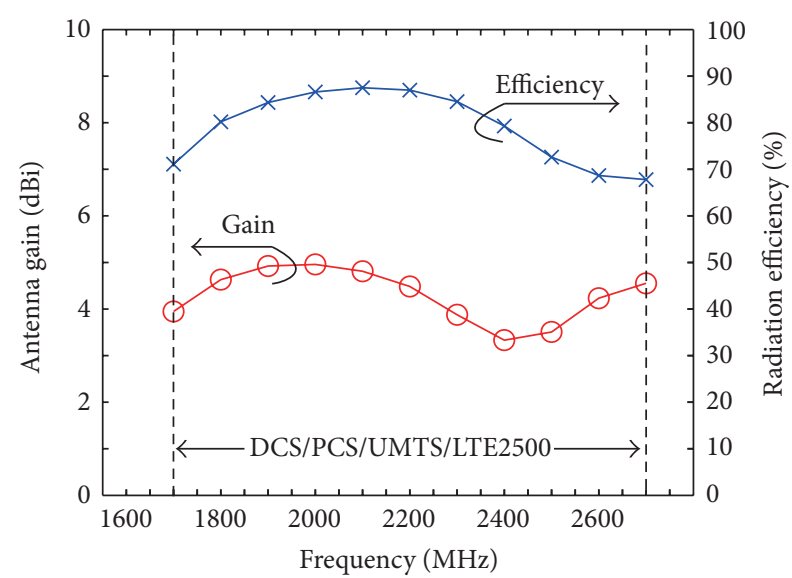

(b)

FIGURE 11: Measured antenna gain of the proposed antenna at (a) lower band and (b) upper band. 
results indicate that the proposed antenna is suitable to be applied in the modern slim mobile phone.

\section{Conflict of Interests}

The authors declare that there is no conflict of interests regarding the publication of this paper.

\section{References}

[1] D.-G. Kang and Y. Sung, "Planar printed shorted monopole antenna with coupled feed for LTE/WWAN mobile handset applications," International Journal of Antennas and Propagation, vol. 2013, Article ID 151864, 6 pages, 2013.

[2] H. F. Abutarboush, R. Nilavalan, T. Peter, and S. W. Cheung, "Multiband inverted-f antenna with independent bands for small and slim cellular mobile handsets," IEEE Transactions on Antennas and Propagation, vol. 59, no. 7, pp. 2636-2645, 2011.

[3] S.-C. Chen and K.-L. Wong, "Wideband monopole antenna coupled with a chip-inductor-loaded shorted strip for LTE/ WWAN mobile handset," Microwave and Optical Technology Letters, vol. 53, no. 6, pp. 1293-1298, 2011.

[4] C.-T. Lee and K.-L. Wong, "Planar monopole with a coupling feed and an inductive shorting strip for LTE/GSM/UMTS operation in the mobile phone," IEEE Transactions on Antennas and Propagation, vol. 58, no. 7, pp. 2479-2483, 2010.

[5] Z. Zhong, Y. Li, Z. Liang, and Y. Long, "Biplanar monopole with DSPSL feed and coupling line for broadband mobile phone," IEEE Antennas and Wireless Propagation Letters, vol. 11, pp. 1326-1329, 2012.

[6] Q. Luo, H. P. Tian, Z. T. Huang, X. D. Wang, Z. Guo, and Y. F. Ji, "Unidirectional dual-band CPW-fed antenna loaded with an AMC reflector," International Journal of Antennas and Propagation, vol. 2013, Article ID 875281, 10 pages, 2013.

[7] H.-D. Chen and H.-T. Chen, "A CPW-fed dual-frequency monopole antenna," IEEE Transactions on Antennas and Propagation, vol. 52, no. 4, pp. 978-982, 2004.

[8] Z.-L. Zhou, L. Li, and J.-S. Hong, "Novel compact CPW-fed antennas with harmonic suppression and bandwidth enhancement," International Journal of Antennas and Propagation, vol. 2012, Article ID 589467, 8 pages, 2012.

[9] Y. Jee and Y.-M. Seo, "Triple-band CPW-fed compact monopole antennas for GSM/PCS/DCS/WCDMA applications," Electronics Letters, vol. 45, no. 9, pp. 446-448, 2009.

[10] K. G. Thomas and M. Sreenivasan, "Compact CPW-fed dualband antenna," Electronics Letters, vol. 46, no. 1, pp. 13-14, 2010.

[11] Y. S. Li, W. X. Li, and Q. B. Ye, "A CPW-fed circular wide-slot UWB antenna with wide tunable and flexible reconfigurable dual notch bands," The Scientific World Journal, vol. 2013, Article ID 402914, 10 pages, 2013.

[12] C. Yoon, W.-S. Kim, G.-T. Jeong, S.-H. Choi, H.-C. Lee, and H.D. Park, "A planar CPW-fed patch antenna on thin substrate for broadband operation of ISM-band applications," Microwave and Optical Technology Letters, vol. 54, no. 9, pp. 2199-2202, 2012.

[13] O. T.-C. Chen and C.-Y. Tsai, "CPW-fed wideband printed dipole antenna for digital TV applications," IEEE Transactions on Antennas and Propagation, vol. 59, no. 12, pp. 4826-4830, 2011.

[14] D. M. Pozar, Microwave Engineering, Wiley, New York, NY, USA, 2011.
[15] I. J. Bahl and D. K. Trivedi, "A designer's guide to microstrip line," Microwaves, vol. 16, no. 5, pp. 174-182, 1977.

[16] K. C. Gupta, R. Garg, and I. J. Bahl, Microstrip Lines and Slotlines, vol. 1979, Artech House, Dedham, Mass, USA. 

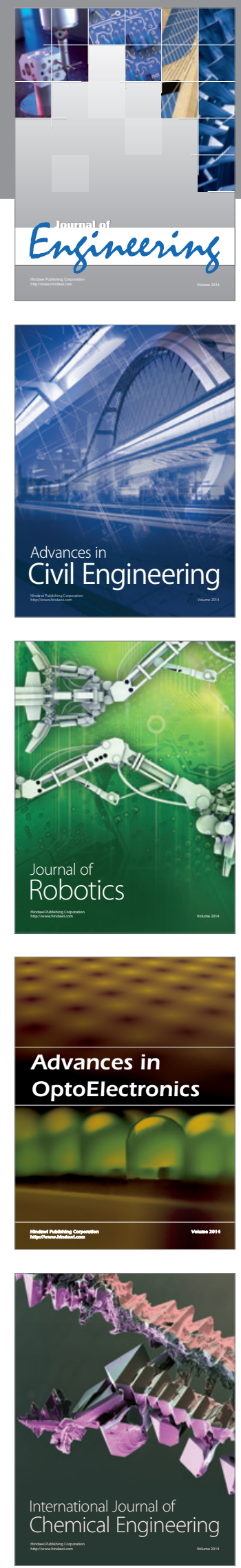

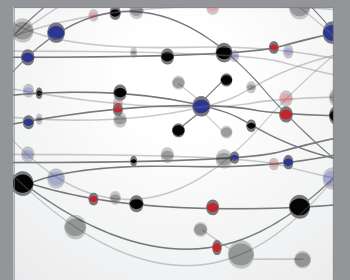

The Scientific World Journal
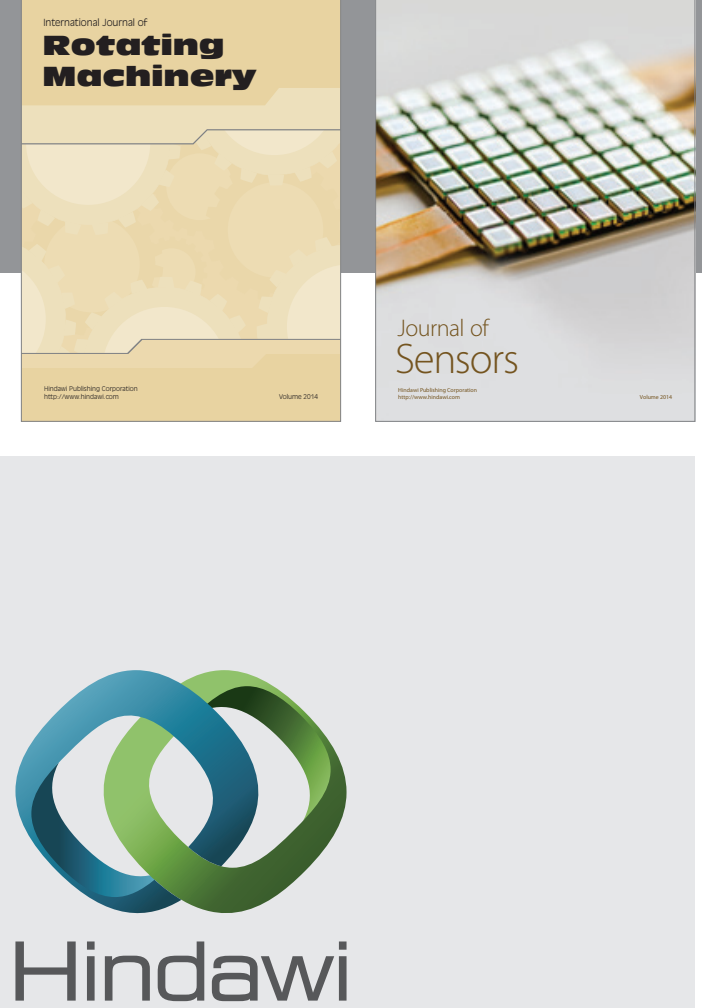

Submit your manuscripts at http://www.hindawi.com
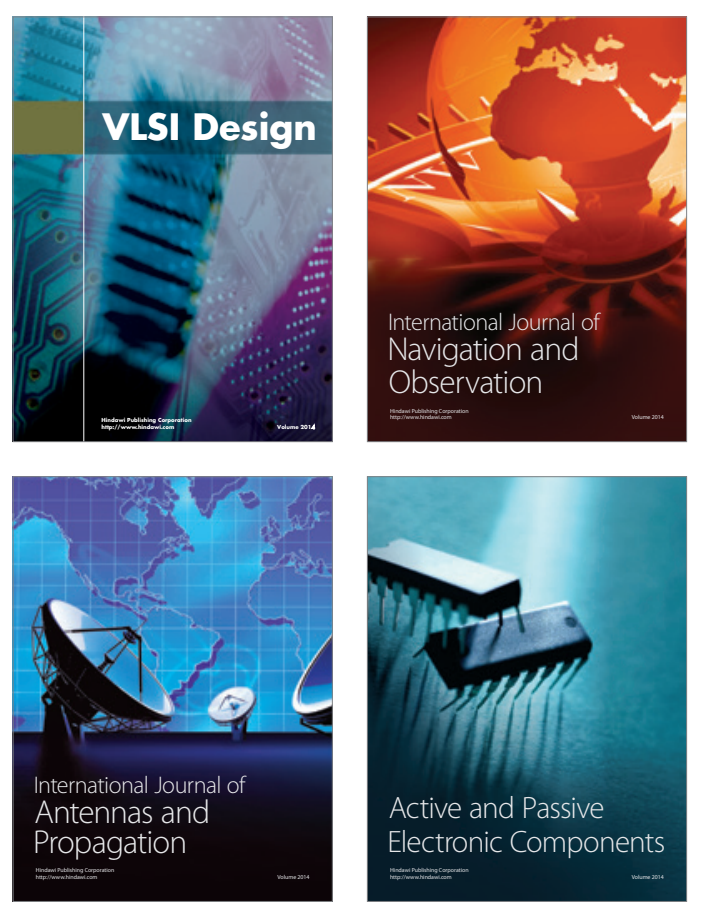
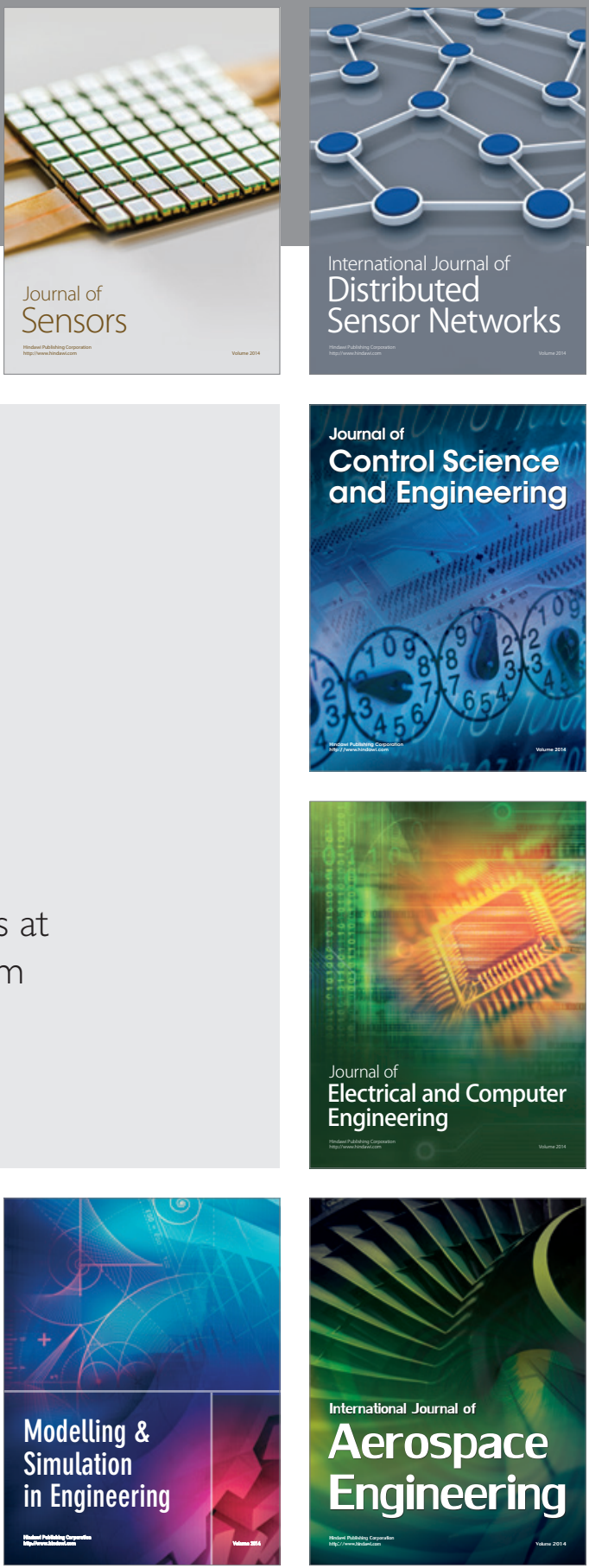

Journal of

Control Science

and Engineering
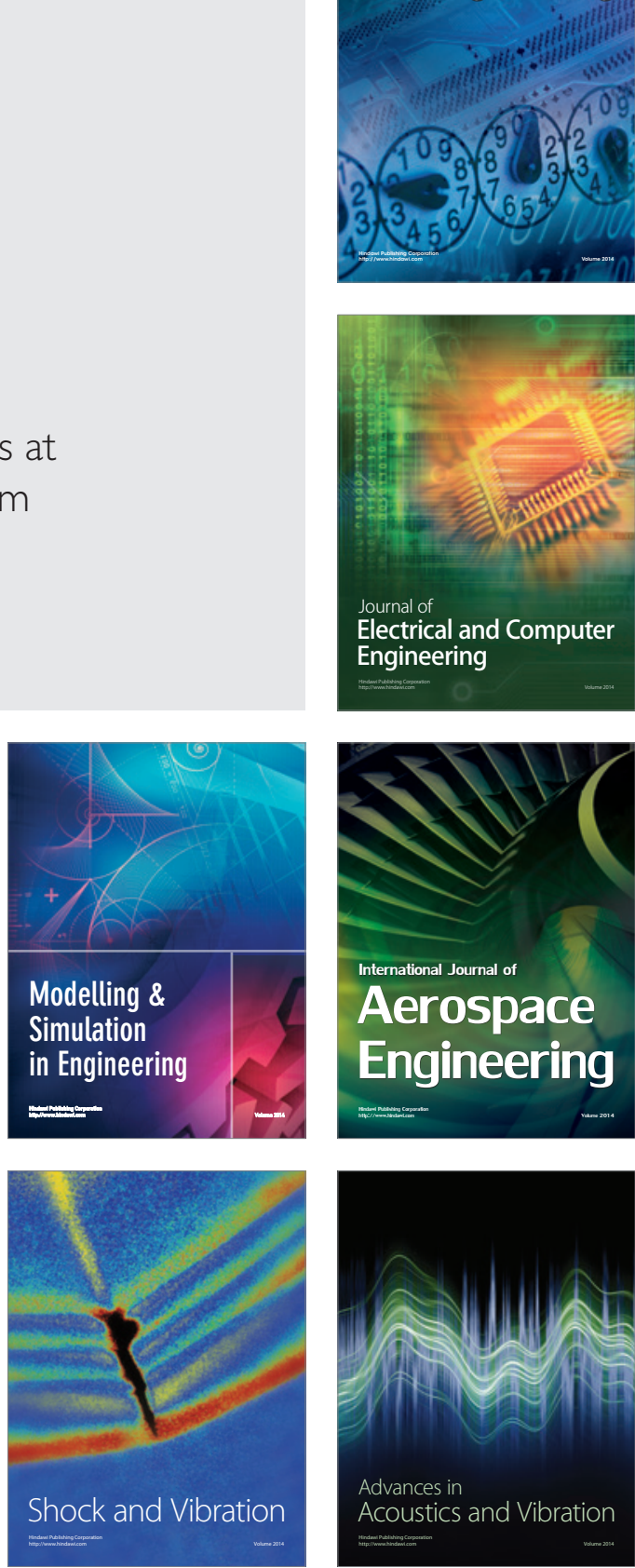